\title{
Investigation of human papillomaviruses (HPV), mouse mammary tumour virus (MMTV), Epstein-Barr virus (EBV), and human polyomavirus entities in canine mammary tumours
}

\author{
Kivilcim Sonmez ${ }^{1}$, Eda Altan ${ }^{2}$, Funda Yildirim ${ }^{1}$, Seçkin Serdar Arun ${ }^{1}$, \\ Nuri Turan ${ }^{2}$, Huseyin Yilmaz ${ }^{2}$, Mert Ahmet Kuskucu ${ }^{3}$ \\ ${ }^{1}$ Pathology Department, ${ }^{2}$ Virology Department, Veterinary Faculty, \\ Istanbul University, 34320, Avcilar, Istanbul, Turkey \\ ${ }^{3}$ Microbiology and Clinical Bacteriology Department, Cerraphasa Medicine Faculty, \\ Istanbul University, 34098, Fatih, Istanbul, Turkey \\ kivilcim@istanbul.edu.tr
}

Received: August 28, $2015 \quad$ Accepted: February 2, 2016

\begin{abstract}
Introduction: The aim of the study was to investigate the presence of human papillomaviruses (HPV), mouse mammary tumour virus (MMTV), Epstein-Barr virus (EBV), and human polyomavirus BK in canine mammary tumours (CMTs) and to correlate the results of histopathological classification with the results of virological examination. Material and Methods: Eighty CMTs and ten normal canine mammary gland samples were evaluated using histopathological methods and TaqMan real-time PCR analysis. Results: The results indicated that all mammary tumours and normal mammary tissue samples were negative for HPV16 and other HPV, EBV, human polyomavirus, and human mammary tumour virus strains. Conclusion: Further studies should be performed to investigate the existence of other strains of HPV, EBV, and human polyomavirus in CMTs.
\end{abstract}

Keywords: dogs, canine mammary tumours, EBV, BKV, HPV, MMTV.

\section{Introduction}

Mammary gland tumours are common malignancies of dogs and constitute $50 \%$ of all neoplasms $(17,18,20)$. In comparative research on human and canine mammary tumours (CMTs), it was reported that CMTs are better suited than rodent models to the evaluation of the molecular mechanism of carcinogenesis $(10,11,19)$.

The possibility that viruses may have a role in breast cancer (BC) aetiology was first posited in 1936 by John Bittner and colleagues at the Jackson Laboratory in Maine (3). They observed that mouse milk contained an unknown factor that caused mammary tumours in their pups when they attained adulthood. This unknown factor was later identified as mouse mammary tumour virus (MMTV).
Many studies have evaluated viruses in human tumours and $\mathrm{BC}$ as a potential aetiological factor $(1,4$, $9,16)$. In virus-associated cancer, the viral infection causes a malignant transformation of the host's infected cells. Human papillomaviruses (HPV), MMTV, and Epstein-Barr (EBV) viruses are prime candidates as agents of human BC (1). In a previous study, MMTV was detected in $\mathrm{BC}$, but not in normal breast tissue, and the study also reported that the virus spread rapidly in human BC cell cultures (1).

Although the exact role of viruses in tumour development is not clear, it is known that viruses may contribute to the development of human tumours by different mechanisms: indirectly by inducing immunosuppression or by modifying the host cell genome without persistence of viral DNA; and directly by inducing oncoproteins or by altering the expression 
of host cell proteins at the site of viral DNA integration (1). Due to these effects, Lawson and Heng (13) believed that the scientific issue has evolved from "are viruses present in BC?" to "are viruses in BC oncogenic or harmless passengers?" They also stated that the key candidate viruses and their potential causal role in $\mathrm{BC}$ should be taken into consideration.

Polyomaviruses (PVs) are a group of epitheliatropic viruses found in a wide variety of species. They cause benign epithelial proliferations but have also been linked to tumours in animals and humans (6). Hachana et al. (5) detected human polyomavirus DNA with an oncogenic character in $\mathrm{BC}$.

To the best of our knowledge, only Hsu et al. (8) have investigated MMTV-like sequences in canine and feline mammary tumours and normal mammary tissues (not in cell lines), but EBV, HPV, and PV have never been investigated as aetiological factors. Thus, the aim of this study was to evaluate the possible pathogenic properties of these viruses in dog mammary tumours. We also aimed to investigate the neoplastic and normal mammary gland tissue of dogs in close relation with humans using TaqMan real-time PCR. Moreover, we also intended to evaluate the correlation between these agents and the histopathological classification of the tumours.

\section{Material and Methods}

Samples. Eighty dog neoplastic tissues submitted to the Pathology Department with indications of mammary tumour and ten normal mammary tissues from necropsies were used in the study. Among the animals whose neoplastic tissues were used, 50\% $(40 / 80)$ were spayed at a young age (1-3 years) and $17.5 \%(14 / 80)$ gave birth at a young age (2-3 years). The animals whose tissues were collected as control were not spayed and had not given birth at an early age.
Collected tissue samples were immediately frozen in liquid nitrogen and kept at $-80^{\circ} \mathrm{C}$ until the polymerase chain reaction (PCR) analysis.

Histopathology. About 4-5 $\mu$ m-thick paraffin sections were stained with haematoxylin and eosin, evaluated under a light microscope, and classified according to the WHO classification (17). The existence of koilocytes (nuclear enlargement with clear perinuclear cytoplasmic halo), which were accepted as pathognomonic for HPV (12), was also evaluated.

DNA extraction. The commercial PureLink Genomic DNA Mini Kit (Invitrogen, USA) was used for DNA extraction. About $25 \mathrm{mg}$ of tissue samples were taken and $100 \mu \mathrm{L}$ of nuclease-free water was added. Then DNA was extracted according to the manufacturer's instructions. The amount of DNA in the extracts was measured with NanoDrop (NanoDrop, part of Thermo Fisher Scientific, USA). The DNA samples were then kept at $-80^{\circ} \mathrm{C}$ until the PCR analysis.

TaqMan real-time PCR assay. The presence of HPV-16, EBV BALF 5, MMTV, and human polyomavirus $\mathrm{BK}$ in canine mammary tumours was tested with TaqMan real-time PCR. The primer and probe sequences were selected and synthesised by a commercial company (DNA Technology, Denmark) (Table 1). Then TaqMan real-time PCR analyses were performed using an average of $100 \mathrm{ng} / \mu \mathrm{l}$ of the DNA. The positive controls used in the study are given in Table 2. Negative controls for the TaqMan real-time PCR included RNA extracted from negative dog tissues and a reaction mixture with nuclease-free water in place of the template.

Biorad Chromo4 (USA) was used for TaqMan real-time PCR analyses. Oligonucleotides designed for EBV BALF 5 were diluted in the range of $10^{-2}-10^{-9}$ for optimisation and $10^{-5}$ dilution was used as positive control for further studies. After the PCR analyses, the products were visualised in $1.5 \%$ agar gel electrophoreses.

Table 1. Primer sequences used in the study

\begin{tabular}{|c|c|c|}
\hline Primer name & Sequence & References \\
\hline $\mathrm{ABL}$ & TAGTTCCCCATACAGAATTGTTTCGCT & \multirow{5}{*}{ Bindra et. al. (2) } \\
\hline $\mathrm{ABR}$ & TCATCACCAATATCTACAGGTAGCAGCAC & \\
\hline ABL1 & TAGTCCCCCATACAGAATTGTTTCGCT & \\
\hline ABR1 & TCATCACCAATATCTACAGGTAGCAGTGAC & \\
\hline $\mathrm{ABP}$ & FAM-ACTATGATCGCT*(TAMRA)GCATAGTCGTAGGCAGAAGAATCT-phosphate-3’ & \\
\hline HPV16F & TTGCAGATCATCAAGAACACGTAGA & \multirow{3}{*}{ Lindh et. al. (14) } \\
\hline HPV16R & CAGTAGAGATCAGTTGTCTCTGGTTGC & \\
\hline HPV16P & FAM-AATCATGCATGGAGATACACCTACATTGCATGA-TAMRA & \\
\hline BALFF & CGGAAGCCCTCTGGACTTC & \multirow{3}{*}{ Perrigoue et. al. (21) } \\
\hline BALFR & CCCTGTTTATCCGATGGAATG & \\
\hline BALFP & FAM-TGTACACGCACGAGAAATGCGCC-TAMRA & \\
\hline BKV F & СTTTCTTTTTTTTTTGGGTGGTGTT & \multirow{3}{*}{ McNees et. al. (15) } \\
\hline BKV R & TTGCCAGTGATGAAGAAGCAA & \\
\hline BKV P & FAM-AGTGTTGAGAATCTGC-TAMRA & \\
\hline
\end{tabular}




\section{Results}

Histopathology. The histomorphology of sections was evaluated and classified according to the WHO classification. The number of samples in each classification is given in Table 3 . No significant koilocyte formation was detected in any of the sections.

TaqMan real-time PCR assay. Serial dilutions of EBV-BALF 5 oligonucleotide were made for optimisation, and the following threshold cycles values
$\left(\mathrm{C}_{T}\right)$ were observed: 16 at $10^{-2}, 20$ at $10^{-3}, 23$ at $10^{-4}, 26$ at $10^{-5}, 29$ at $10^{-6}, 32$ at $10^{-7}, 34$ at $10^{-8}$, and 35 at $10^{-9}$ (Fig. 1). $\mathrm{C}_{T}$ values of 14 and 28 were obtained respectively with the MMTV and HPV-16 primer sets and probe assays when using a positive control.

In tumour and normal mammary gland tissues, no HPV16, MMTV, EBV BALF 5, or human polyomavirus BK were detected, although positive control of viruses gave positive signals in PCR.

Table 2. Positive controls used in the study

\begin{tabular}{lll}
\hline $\begin{array}{l}\text { Positive } \\
\text { controls }\end{array}$ & Type & Source \\
\hline HPV-16 & DNA & Microbiology and Clinic Bacteriology Department, Medicine Faculty, Istanbul University Cerrahpasa \\
\hline EBV & Oligonucleotide & $\begin{array}{l}\text { 5'-AAGGCCGGAGGCAGACACCCACGGAAGCCCTCTGGACTTCCATGTCTACGACATACTTGAG } \\
\text { ACGGTGTACACGCACGAGAAATGCGCCGTCATTCCATCGGATAAACAGGGGTATGTGGTG-3 }\end{array}$ \\
\hline MATV 5 & Virus isolate & $\begin{array}{l}\text { ATCC mouse mammary tumour virus (product code: ATCC VR-732), retrovirus, mammalian type B, } \\
\text { oncovirus, strain: RIII MT10 }\end{array}$ \\
\hline
\end{tabular}

Table 3. Distribution of tumour cases according to WHO canine mammary tumour classification

\begin{tabular}{|c|c|c|}
\hline \multicolumn{2}{|c|}{ Classification of WHO } & Number of tumour cases $(\%)$ \\
\hline \multirow{17}{*}{ 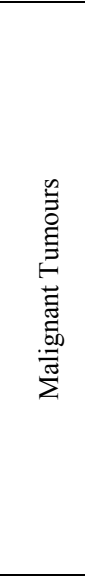 } & Non-infiltrating (in situ) carcinoma & $2(2.50 \%)$ \\
\hline & Complex carcinoma & $13(16.25 \%)$ \\
\hline & \multicolumn{2}{|l|}{ Simple carcinoma } \\
\hline & Tubulopapillary carcinoma & $23(28.25 \%)$ \\
\hline & Solid carcinoma & $15(18.75 \%)$ \\
\hline & Anaplastic carcinoma & $6(7.5 \%)$ \\
\hline & \multicolumn{2}{|l|}{ Special types of carcinoma } \\
\hline & Spindle cell carcinoma & $6(7.5 \%)$ \\
\hline & Squamous cell carcinoma & $1(1.25 \%)$ \\
\hline & Mucinous carcinoma & - \\
\hline & Lipid-rich carcinoma & - \\
\hline & \multicolumn{2}{|l|}{ Sarcoma } \\
\hline & Fibrosarcoma & - \\
\hline & Osteosarcoma & $1(1.25 \%)$ \\
\hline & Other sarcomas & $3(3.75 \%)$ \\
\hline & Carcinosarcoma & $7(8.75 \%)$ \\
\hline & Carcinoma or sarcoma in benign tumour & - \\
\hline \multirow{9}{*}{ 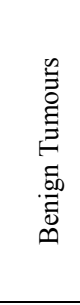 } & Adenoma & \\
\hline & Simple adenoma & $1(1.25 \%)$ \\
\hline & Complex adenoma & - \\
\hline & Basaloid adenoma & - \\
\hline & Fibroadenoma & \\
\hline & Low cellularity fibroadenoma & - \\
\hline & High cellularity fibroadenoma & - \\
\hline & Benign mix tumours & $1(1.25 \%)$ \\
\hline & Duct papilloma & - \\
\hline \multirow{9}{*}{ 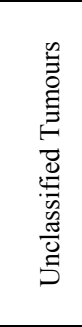 } & Mammary hyperplasia/dysplasia & \\
\hline & Ductal hyperplasia & - \\
\hline & Lobular hyperplasia & \\
\hline & Epithelial hyperplasia & - \\
\hline & Adenosis & $1(1.25 \%)$ \\
\hline & Cysts & - \\
\hline & Duct ectasia & - \\
\hline & Focal fibrosis (fibrosclerosis) & - \\
\hline & Gynaecomastia & - \\
\hline
\end{tabular}




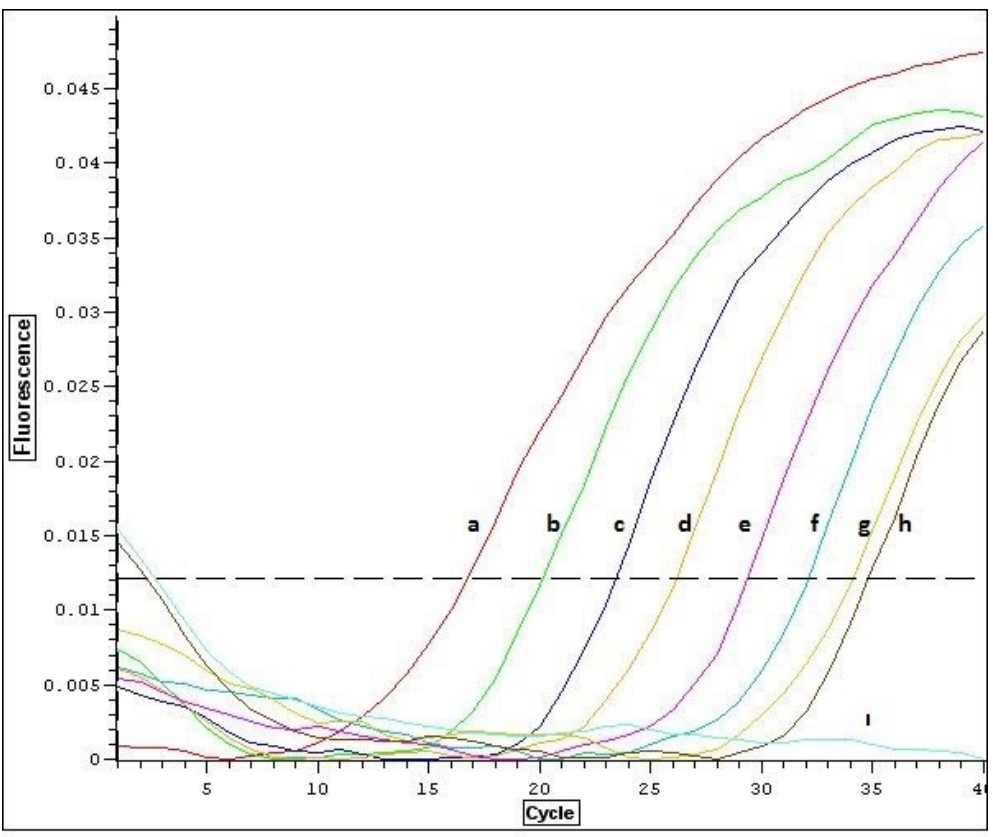

Fig. 1. Oligonucleotide dilutions for BALF-5. $a-10^{-2}, b-10^{-3}, c-10^{-4}, d-10^{-5}, e-10^{-6}$, $\mathrm{f}-10^{-7}, \mathrm{~g}-10^{-8}, \mathrm{~h}-10^{-9}, \mathrm{i}-$ negative control

\section{Discussion}

HPV 11, 16, 18, and 33, polyomavirus SV40, JCV and BKV, EBV BALF 5 and Raji, MMTV, and HMTV have been reported previously $(1,2,5,13,14,21,23)$. In one study (10), conducted in the same geographic areas as our research, normal and tumour tissue samples in BC patients were investigated for HPV DNA frequency and subset analyses. HPV subtypes 11 and 16 were not detected in any of the patients. HPV 33 was positive in $96.4 \%$ of the tumour tissue samples and $87.5 \%$ of the normal tissue samples. Due to certain financial limitations, only the presence of HPV-16, EBV BALF 5, MMTV, and human polyomavirus BK was investigated in the present study. We could not evaluate HPV 33; however, most of the cases studied by Gumus et al. (10) were HPV 33-positive.

Only a few studies have compared histomorphological classification of $\mathrm{BC}$ and viral involvement in invasive/non-invasive ductal carcinoma. Hachana et al. (5) detected 12 polyomavirus-positive tissues in 112 cases of invasive ductal carcinoma. Lawson and Heng (13) reported that $85 \%$ of HPV, EBV, and MMTV cases were invasive/non-invasive ductal carcinoma. According to the WHO classification (17) (Table 3) there is no classification regarding to ductal carcinoma of canine mammary tumours. We think that this diversity arises from physiological, anatomical, and ergonomic differences among species, and the mechanism of the viral aetiology may be affected due to these differences.

Previous reports on $\mathrm{BC}$ and its viral aetiology have shown that the presence of viruses can be influenced by epidemiologic factors, including hormone levels $(7,23)$. Wang et al. (23) reported that the prevalence of MMTV-like virus sequences in human gestational $\mathrm{BC}$ (cancer during pregnancy or 12 months post-partum) is as high as $62 \%$ compared with the $30 \%-38 \%$ prevalence of such sequences in sporadic $\mathrm{BCs}$, which may suggest an influence of hormones on MMTV-like viruses. In the presented study, no tumour tissue was used from animals which were pregnant or 12 months after a pregnancy. In addition, Highman et al. (7) reported that oestrogens induce mouse mammary tumours only in the presence of MMTV. This may indicate that the presence of oestrogen is essential for the viral aetiology of MMTV. Since half of the animals included in the study were spayed at young ages, they had very low levels of oestrogen. If the ability of viruses to generate tumours depends on the presence of oestrogen and/or progesterone, then the low oestrogen status of half of the sample in our study decreased viral prevalence by half.

Hsu et al. (8) reported the presence of MMTV-like nucleotide sequences in canine and feline mammary tumours. They used the nested PCR method in CMT tissues and detected $3.49 \%$ of MMTV-like env and LTR sequences. Although we used the TaqMan realtime PCR and MMTV isolate as a positive control, we did not detect MMTV in our CMT tissue samples. This difference may be due to the previously described relationship between MMTV and $\mathrm{BC}$ and the presence of house mouse in the domestic or work environment $(13,23)$. Stewart et al. (21) predicted that "people who live and work where Mus domesticus is especially common should have a higher MMTV sero-prevalence than those not so directly exposed to mice". They also reported that the high incidence of MMTV DNA is 
expected in tumours from patients living in Western Europe, South America, Australia, New Zealand, and Hawaii, rather than those living in Eastern Europe or Asia.

Further studies should be performed to investigate the existence of other strains of HPV, EBV, and human polyomavirus in CMTs. The influence of differences in physiological and anatomical features among species on viral aetiology of tumours should be evaluated, considering various epidemiological factors, such as hormone levels or mouse populations.

Conflict of Interests Statement: The authors declare that they have no conflict of interests regarding the publication of this article.

Financial Disclosure Statement: This study was supported by the Istanbul University Scientific Research Projects Unit (Project Number: 25208).

Animal Rights Statement: None required.

\section{References}

1. Amarante M.K., Watanabe M.A.: The possible involvement of virus in breast cancer. J Cancer Res Clin 2009, 135, 329-337.

2. Bindra A., Muradrasoli S., Kisekka R., Nordgren H., Wärnberg F., Blomberg J.: Search for DNA of exogenous mouse mammary tumour virus-related virus in human breast cancer samples. J Gen Virol 2007, 88, 1806-1809.

3. Bittner J.J.: Some possible effects of nursing on the mammary gland tumour incidence in mice. Science 1936, 84, 162.

4. Gumus M., Yumuk P.F., Salepci T., Aliustaoglu M., Dane F., Ekenel M., Basaran G., Kaya H., Barisik N., Turhal N.S.: HPV DNA frequency and subset analysis in human breast cancer patients' normal and tumoral tissue samples. J Exp Clin Cancer Res 2006, 25, 515-521.

5. Hachana M., Amara K., Ziadi S., Gacem R.B., Korbi S., Trimeche M.: Investigation of human JC and BK polyomaviruses in breast carcinomas. Breast Cancer Res Treat 2012, 133, 969-977.

6. Hausen H.Z.: Viruses in human cancers. Science 1991, 254, 1167-1173.

7. Highman B., Norvell M.J., Shellenberger T.E.: Pathological changes in female $\mathrm{C} 3 \mathrm{H}$ mice continuously fed diets containing diethylstilboestrol or 17-estradiol. J Environ Pathol Toxicol 1978, 1, 1-30.

8. Hsu W.L., Lin H.Y., Chiou S.S., Chang C.C., Wang S.P., Lin K.H., Chulakasian S., Wong M.L., Chang S.C.: Mouse mammary tumour virus-like nucleotide sequences in canine and feline mammary tumours. J Clin Microbiol 2010, 48, 4354-4362.

9. Javier R.T., Butel J.S.: The history of tumour virology. Cancer Res 2008, 68, 7693-7706.

10. Kumaraguruparan R., Karunagaran D., Balachandran C., Manohar B.M., Nagini S.: Of humans and canines: a comparative evaluation of heat shock and apoptosis-associated proteins in mammary tumors. Clin Chim Acta 2006, 365, $168-176$.

11. Kumaraguruparan R., Prathiba D., Nagini S.: Of humans and canines: immunohistochemical analysis of PCNA, Bcl-2, p53, cytokeratin and ER in mammary tumours. Res Vet Sci 2006, 81, 218-224.

12. Lawson J.S., Glenn W.K., Heng B., Ye Y., Tran B., LutzeMann L., Whitaker N.J.: Koilocytes indicate a role for human papilloma virus in breast cancer. Br J Cancer 2009, 1, 1351-1356.

13. Lawson J.S., Heng B.: Viruses and Breast Cancer. Cancers 2010, 2, 752-772.

14. Lindh M., Görander S., Andersson E., Horal P., MattsbyBalzer I., Rydc W.: Real-time Taqman PCR targeting 14 human papilloma virus types. J Clin Virol 2007, 40, 321-324.

15. McNees A.L., White Z.S., Zanwar P., Vilchez R.A., Butel J.S.: Specific and quantitative detection of human polyomaviruses BKV, JCV, and SV40 by real time PCR. J Clin Virol 2005, 34, 52-62.

16. Mesa-Tejada R., Keydar I., Ramanarayanan M., Ohno T., Fenoglio C., Spiegelman S.: Immunohistochemical detection of a cross-reacting virus antigen in mouse mammary tumours and human breast carcinomas. J Histochem Cytochem 1978, 26, 532-541.

17. Misdorp W.: Tumours of the mammary gland. In: Tumours in Domestic Animals, edited by Meuten D.J., Iowa State Press, Ames, USA, 2002, pp. 575-606.

18. Moulton J.E.: Tumours of the mammary gland. In: Tumours in Domestic Animals, edited by Moulton J.E., University of California Press, London, 1978, pp. 346-371.

19. Nerurkar V.R., Chitale A.R., Jalnapurkar B.V., Naik S.N., Lalitha V.S.: Compatarive pathology of canine mammary tumours. J Comp Pathol 1989, 101, 389-397.

20. Owen L.N.: A comparative study of canine and human breast cancer. Invest Cell Pathol 1979, 2, 257-275.

21. Perrigoue J.G., den Boon J.A., Friedl A., Newton M.A., Ahlquist P., Sugden B.: Lack of association between EBV and breast carcinoma. Cancer Epidem Biomar 2005, 14, 809-814.

22. Stewart T.H.M., Sage R.D., Stewart A.F.R., Cameron D.W.: Breast cancer incidence highest in the range of one species of house mouse, Mus domesticus. Br J Cancer 2000, 82, 446-451.

23. Wang Y., Melana S.M., Baker B., Bleiweiss I., FernandezCobo M., Mandeli J.F., Holland J.F., Pogo B.G.T.: High prevalence of MMTV-like env gene sequences in gestational breast cancer. Med Oncol 2003, 20, 233-236. 